\title{
A novel and smart automatic light-seeking flowerpot for monitoring flower growth environment
}

\author{
Xihai Zhang, Dong Liu, Chengguo Fan, Jiali Du, Fanfeng Meng, Junlong Fang ${ }^{*}$ \\ (School of Electronic Engineering and Information, Northeast Agricultural University, Harbin 150030, China)
}

\begin{abstract}
Although the flowerpot is widely used for indoor flowers, it cannot meet the needs of intelligent management during the uncared-for period. The objective of this study was to design a new microcontroller-based smart flowerpot. Its overall system was composed of three parts: information collection layer, automatic control layer and data transmission layer. Firstly, in the process of collecting information, the Laiyite criterion and the normalized weighted average algorithm were adopted to improve the accuracy of information collection. Secondly, for making precise control decisions, the fuzzy control was used to achieve automatic on-demand watering. Finally, the method for comparative analysis of regional light intensity was utilized to achieve light-seeking and light-supplementing. Experimental results showed that the smart flowerpot had strong anti-jamming performance for information collection, the relative soil moisture of flowers could be stably maintained near the optimum humidity $(65 \%)$, and the light was well-distributed on the flower with the error angle of light-supplementing ranged from $-3^{\circ}$ to $3^{\circ}$.
\end{abstract}

Keywords: smart flowerpot, automatic watering, seeking light, supplementing light control, microcontroller DOI: $10.25165 /$ j.ijabe. 20181102.2786

Citation: Zhang X H, Liu D, Fan C G, Du J L, Meng F F, Fang J L. A novel and smart automatic light-seeking flowerpot for monitoring flower growth environment. Int J Agric \& Biol Eng, 2018; 11(2): 184-189.

\section{Introduction}

With the continuous development of social economy, the quality of life of people is continuously improved. The demand for indoor afforestation is also growing. However, the living environment is deteriorating and the air quality is also getting worse in the industrial developed cities of China. As everyone knows, the flowers can release stress and purify indoor air and so on. Reasonable watering and proper light are not only beneficial to the growth of plants, but also to highly efficient use of water resources and light energy ${ }^{[1]}$. At present, the planting and management of flowers are still highly dependent on manual operation, so that survival rate is relatively low.

The development of modern electronic technology, sensor technology and communication technology provides effective methods for the collection of environment information ${ }^{[2-4]}$. In recent years, some researches were conducted on real-time monitoring systems of the smart flowerpot. Wu et al. ${ }^{[5]}$ designed an ARDUINO microcontroller-based smart flowerpot which has the voice broadcast function and can achieve automatic watering. Lea-Cox et al. ${ }^{[6]}$ studied a smart wireless sensor node that is capable of integrating outputs from a range of soil moisture

Received date: $2016-08-13 \quad$ Accepted date: 2017-02-10

Biographies: Xihai Zhang, $\mathrm{PhD}$, Associate Professor, research interests: internet of things, unmanned aerial vehicle, Email: xhzhang@neau.edu.cn; Dong Liu, Master candidate, research interests: internet of things, Email: 18846820376@163.com; Chengguo Fan, Master candidate, research interests: unmanned aerial vehicle, Email: georgefanaaa@126.com; Jiali Du, Master candidate, research interests: internet of things, Email: 18846428924@163.com; Fanfeng Meng, PhD, Lecturer, research interests: control theory, Email: meng_fanfeng@sina.cn.

*Corresponding Author: Junlong Fang, PhD, Professor, research interests: internet of things, agricultural electrification, Northeast Agricultural University, No.600, Changjiang Road, Xiangfang District, Harbin 150030, China. Tel: +86-451-55190468, Email: jlfang@neau.edu.cn. and environmental sensors for pot-in-pot nursery. The sensor-controlled technology is used to make precision watering decision on a daily basis. Zhang et al. ${ }^{[7]}$ proposed an automatic irrigation device for potted plants based on Programmable Logic Controller. It used the pressure sensor to measure the weight of potted plants, and used the bar code reader to read the information of potted plants. Ji et al. ${ }^{[8]}$ designed a smart pot based on the combination of ZigBee and ESP8266. It can upload the diverse plant growth data collected from the system to cloud server of internet. The above mentioned flowerpots have their own characteristics, and their functions are powerful enough. But further improvements are still needed in some aspects. Firstly, using a single sensor may lead to the poor accuracy of collected information and weak ability to resist the random interference. Therefore, the collected information is not the true value of the state, so that the growth state of the plant can't be accurately judged. Secondly, although the function of automatic watering is achieved, it can not water the flowers in accordance with the actual need, so it is difficult to achieve the ideal control effect. Finally, most of the above mentioned designs can detect the environment light, but the corresponding decision can't be made when the light intensity is uneven or inadequate. All of the above mentioned problems may affect the life of flowers.

This paper comes up with a new smart flowerpot. In addition to the above mentioned functions, the corresponding improvement methods are put forward to overcome the drawbacks. Firstly, the smart flowerpot can monitor the environment information including soil temperature, humidity, light and water level by various environment sensors. Moreover, the Laiyite criterion and normalized weighted average data fusion algorithm are adopted to achieve accurate information collection and enhance the anti-jamming ability of the collection system. Secondly, the fuzzy control algorithm used in this paper can realize automatic watering control. Lastly, the flowerpot can be rotated automatically by four motors, and the wheels are fixed at the bottom of the flowerpot. 
That helps to automatically seek light and supplement light to make sure the light is well-distributed on the flower.

\section{Materials and methods}

\subsection{Overall design of smart flowerpot}

A modular method is adopted in the design of smart flowerpot. The overall system of smart flowerpot is divided into three layers, namely the information collection layer, the automatic control layer and the data transmission layer. The main function of information collection layer is to collect the flower environmental information which includes temperature, humidity, light intensity, water level and display these information on the LCD screen. The main function of automatic control layer is to achieve automatic watering and light-seeking based on the feedback information. The main function of data transmission layer is to transmit the collected data to a mobile phone APP interface through an ESP8266 wireless WIFI module.

The overall system of the smart flowerpot is shown in Figure 1.

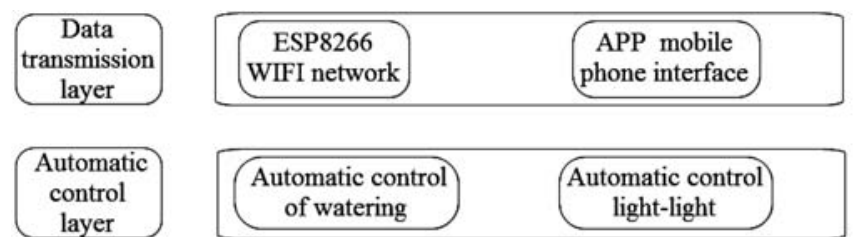

\begin{tabular}{|c|c|c|c|c|c|}
\hline $\begin{array}{c}\text { Information } \\
\text { collection } \\
\text { layer }\end{array}$ & $\begin{array}{c}\text { Humidity } \\
\text { sensor }\end{array}$ & $\begin{array}{l}\text { Light } \\
\text { sensor }\end{array}$ & $\begin{array}{l}\text { Temperatu } \\
\text { re sensor }\end{array}$ & $\begin{array}{c}\text { Water level } \\
\text { sensor }\end{array}$ & $\begin{array}{l}\text { LCD } \\
\text { screen }\end{array}$ \\
\hline
\end{tabular}

a. Overall layout of the system

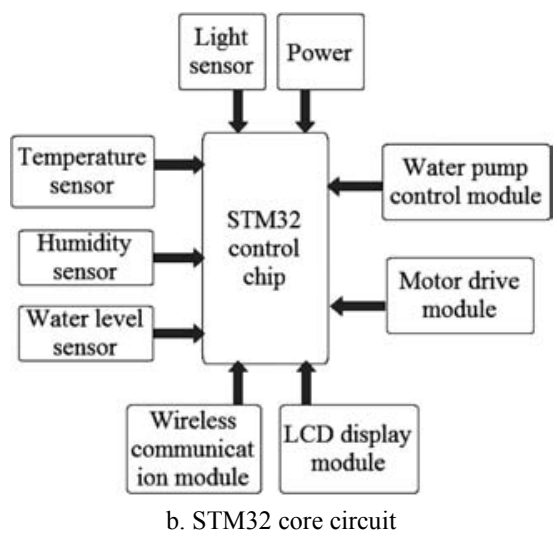

Figure 1 System structure of the smart flowerpot

\subsection{Design of the information collection layer}

2.2.1 Methods for collecting environmental information of flowers

(1) Laiyite criterion

In this collection system, each kind of environmental information is collected with several similar sensors, which has the same precision, and the result of measurement obeys the normal distribution. When the gross error is dealt with, the actual situation and the characteristics of the collection system are fully taken into account, using Laiyite criterion to eliminate the gross error is more appropriate. In the Laiyite criterion, the parameter data which can reflect the distribution structure are residuals and standard deviation estimate. The definition is as follows:

a) When many independent measurements are conducted on a subject, a series of measured values $\left(X_{1}, X_{2}, \ldots, X_{n}\right)$ can be established.

b) The residual of these measurement values is defined as,

$$
V_{i}=X_{i}-\bar{X}
$$

where, $\bar{X}$ is the average value.

c) The estimate of standard deviation is defined as,

$$
\sigma=\sqrt{\frac{1}{n-1} \sum_{i=1}^{n} v_{i}^{2}}
$$

It supposes the measured value obey the normal distribution. If $V_{i}$ satisfies Equation (3), the suspicious gross errors that should be eliminated can be determined in the $X_{i}$.

$$
\left|V_{i}\right|>3 \sigma
$$

(2) The normalized weighted average algorithm

Many same sensors are needed to measure the same parameters from different angles. In this way, the state of the environmental parameter which exists random disturbances can be measured precisely, so that it can be more close to real value. The normalized weighted average fusion algorithm has the advantages of low computation, high precision and simple computer programming, which are suitable for detection of slowly changing variables. The environmental information collection system of flowers has these features, thus this algorithm is adopted ${ }^{[9,10]}$ to obtain accurate information. The specific steps of this algorithm are as follows:

a) The average value of the measured data is calculated. The formula is as presented in Equation (4).

$$
\bar{X}=\frac{1}{n} \sum_{i=1}^{n} X_{i}
$$

b) The deviation value $\Delta X_{i}$ is calculated, the formula is as expressed in Equation (5).

$$
\Delta X_{i}=X_{i}-\bar{X}
$$

c) The deviation value is introduced into weighting function and do normalized processing, the result is $\overline{\Delta b_{i}}$, the formula is

$$
\overline{\Delta b_{i}}=f\left(\Delta X_{i}\right)
$$

4) The weighted value $\bar{b}_{i}$ is obtained by dealing the deviation value with the method of normalization. The formula is

$$
\overline{b_{i}}=\frac{\Delta \bar{b}_{i}}{\sum_{i=1}^{n} \Delta \bar{b}_{i}}
$$

5) The final average value $X^{+}$can be calculated by using the weighted value, the formula is

$$
X^{+}=\sum_{i=1}^{n} X_{i} \times \bar{b}_{i}
$$

In the process of calculating, weight function $f\left(\Delta X_{i}\right)$ can be selected according to different applications. Here, the weight function is chosen according to the empirical formula,

$$
f\left(\Delta X_{i}\right)=\left(\frac{1}{\pi \times \Delta X_{i}}\right) \times \arctan \left(\frac{1}{\Delta X_{i}}\right)
$$

\subsubsection{Selection of sensors}

(1) Soil moisture sensor

Soil moisture is detected by the FC-28 soil moisture sensor which has the advantages of high precision, real-time measurement, and convenient setting ${ }^{[11,12]}$. Soil moisture range is $0-100 \%$ with accuracy of \pm 0.4 . Moreover, it has the widened sensing area, because of this area, the problem that is easy to rust for contacting soil can be prevented, and the service life can be prolonged ${ }^{[13,14]}$.

(2) Soil temperature sensor

The soil temperature is detected by waterproof DS18B20. It has the characteristics of small size, strong anti-interference ability, high precision, less occupied port line. According to the 
characteristics of DS18B20 digital and single bus access, the field temperature is directly transmitted by digital mode of "first line bus", which greatly improves the anti-interference ability.

(3) Light intensity sensor

TSL2561 module is used to detect the environmental light of flowers. It has a direct $\mathrm{I}^{2} \mathrm{C}$ interface which can convert the light intensity to digital signal as the output ${ }^{[15-17]}$.

(4) Water level sensor

Water level sensor is used to determine water level of the inner water storage tank of flowerpot through a series of exposed and parallel wires trace. In this way, it can accomplish the conversion of water quantity to analog signal. The output of the analog value can be read directly by the CPU.

(5) Display module

The display module can provide a good man-machine interface to display all environmental information in real time. It is mainly composed of 3.2 inch TFT-LCD screen which the resolution is $240 \times 320$.

As is shown in Figure 2, LCD screen shows a variety of environmental information. The smart flowerpot can detect and maintain those parameters by itself.

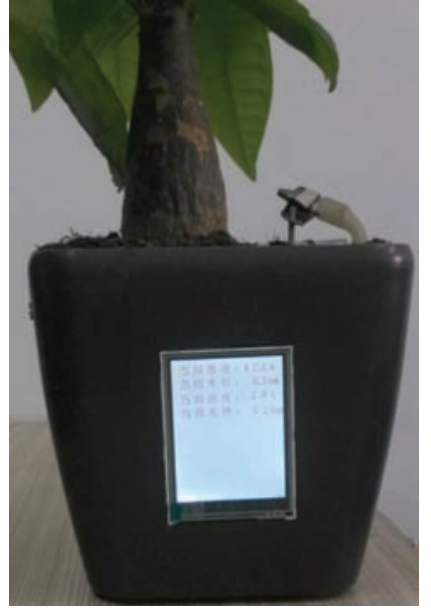

Figure 2 LCD screen display

\subsection{Design of the automatic control layer}

\subsubsection{Automatic watering control}

In order to improve the water utilization rate, fuzzy control is used in the automatic watering control system. The structure of automatic watering fuzzy controller is shown in Figure $3^{[18-20]}$.

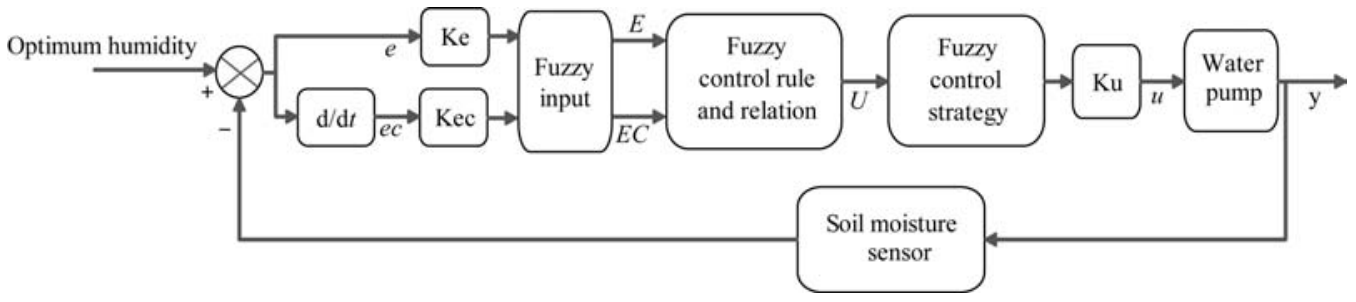

Figure 3 Structure of fuzzy controller

The fuzzy controller is designed in the following procedures. First, $e$ (the error of soil moisture) and $e c$ (error change rate) are designed as the input variables of the fuzzy controller and $u$ (watering time) is designed as its output variable. Second, $E, E C$, $U$ are fuzzy variables which are corresponded to input/output variables of the fuzzy controller, respectively. The fuzzy domain of $E$ and $E C$ are selected from -6 to 6, the fuzzy domain of $U$ is also select from 0 to 6 . The actual conditions and the control precision of watering are fully taken into account, the fuzzy subsets of input and output variables are divided into 7 levels in turn ${ }^{[21-23]}$. $\{N B, N M, N S, Z O, P S, P M, P B\}$ and $\{Z O, P S, P S 1, P M, P M 1, P B$, $P B 1\}$. Finally, the fuzzy rule response table is designed by applying the fuzzy relation $R\left(R=E \times E C \times U=(E \times E C)^{L} \cdot U\right)$ based on the membership assignment table of the fuzzy subset and the fuzzy control model of each variable.

2.3.2 The design of automatic seeking and supplementing light control

According to the feedback information of the detected light intensity, the smart flowerpot can rotate in a definite direction. Firstly, the circular area detected by the light intensity sensor is divided into four small areas, in order to obtain the average light level of each area, several light values are collected in each area when the smart flowerpot is rotating. Then the average values of four small areas are compared. If the light intensity of each area is larger or less than the set value, the flowerpot can keep static state. Otherwise, the weakest light area which the average light is lower than the set value can rotate automatically to the strongest light area in a minimum angle. In this way, it can ensure that the flowers receive uniform light. In order to achieve the automatic rotation, the L293D motor driving module is used to drive four motors which are installed at the bottom of the flowerpot. The modules are shown in Figure 4, and the flow chart is shown in Figure 5.

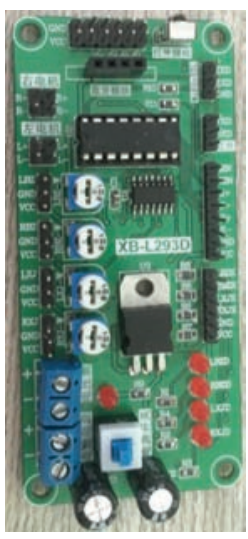

a. L293D driver board

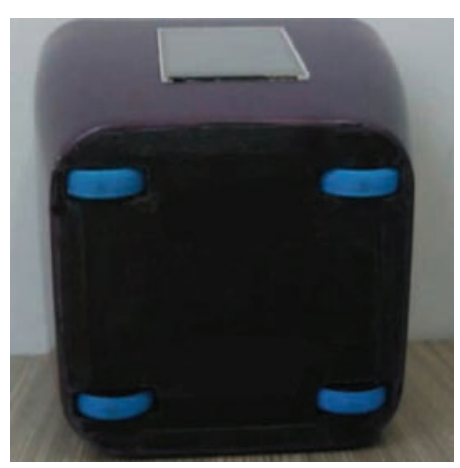

b. Smart flowerpot
Figure 4 L293D motor driving module of smart flowerpot

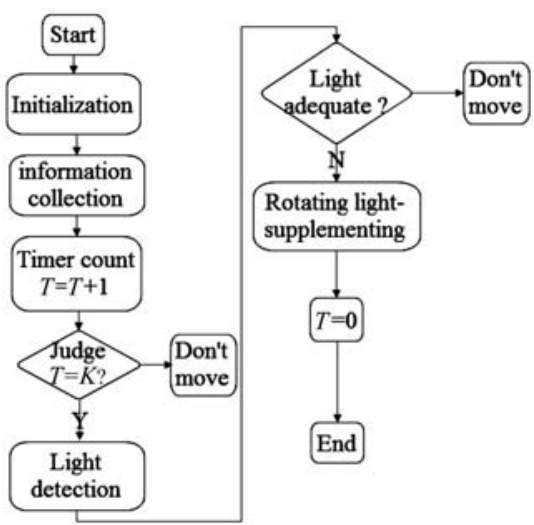

Figure 5 Flow chart of control system 


\subsection{Design of the data transmission layer}

In order to achieve the remote access, in the data transmission layer, the ESP8266 wireless WIFI module is used as the medium to connect the STM32 and the mobile phone to achieve the information exchange ${ }^{[24,25]}$. This system is shown in Figure 6.
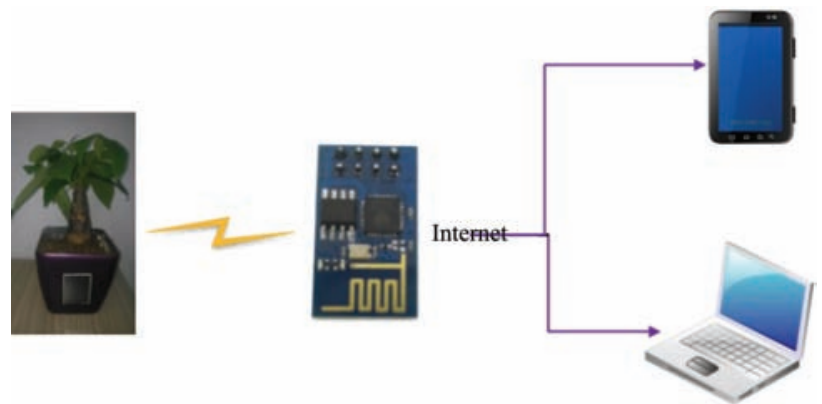

Figure 6 System operating environment

Mobile APP operation interface is shown in Figure 7, the current environmental information of flowers including soil temperature, soil moisture, light intensity, and water level can be displayed in the APP. Mobile APP operation interface shows that the system can rapidly acquire and real-time transmit environmental information, it can provide a basis for intelligent detection and precision watering.

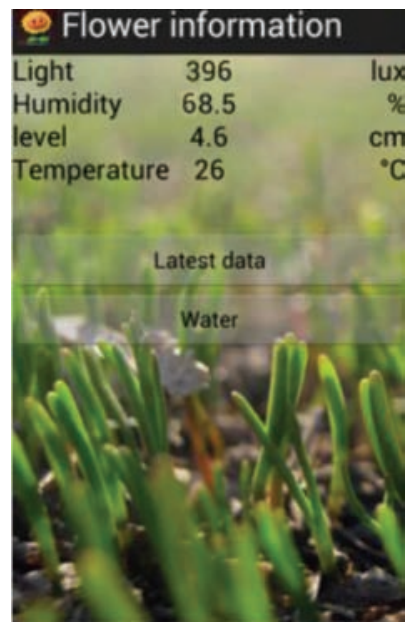

Figure 7 Mobile phone interface

\section{Results and discussion}

\subsection{Anti-jamming performance test}

Taking the humidity as an example, putting three humidity sensors at three different positions in the soil, then the data is recorded and shown in the Table 1. According to the Laiyite criterion and the normalized weighted average algorithm, the weighted average value $\left(X^{+}\right)$can be calculated. The final weighted average values are also shown in Table 1.

The corresponding figures are shown in Figure 8 and Figure 9.

It can be seen that the fluctuation in Figure 8 is relatively smooth in comparison to that in Figure 9. It is obvious that the sixth sets of data measured by sensor 3 existed gross error and poorly reflected the true state of the soil humidity, so the corresponding curve has a larger fluctuation. However, Figure 8 still keeps relatively stable at the corresponding fluctuation point of Figure 9. Therefore, the data measured merely by the sensor is vulnerable to outside interference, and using the proposed algorithm can eliminate the external random dynamic disturbance to improve the measurement accuracy.

Table 1 Humidity acquisition and integration (\%)

\begin{tabular}{|c|c|c|c|c|c|}
\hline \multirow{2}{*}{$\begin{array}{c}\text { Measure } \\
\text { No. }\end{array}$} & \multicolumn{3}{|c|}{ Humidity } & \multirow{2}{*}{$\overline{X_{(3)}}$} & \multirow{2}{*}{$X^{+}$} \\
\hline & Sensor 1 & Sensor 2 & Sensor 3 & & \\
\hline 1 & 67.5 & 68.7 & 68.7 & 68.3 & 68.3 \\
\hline 2 & 67.5 & 69.1 & 68.5 & 68.4 & 68.5 \\
\hline 3 & 67.4 & 68.8 & 68.6 & 68.3 & 68.5 \\
\hline 4 & 67.3 & 68.5 & 68.7 & 68.2 & 68.4 \\
\hline 5 & 67.3 & 68.6 & 68.5 & 68.1 & 68.3 \\
\hline 6 & 67.5 & 68.6 & 90.3 & 75.5 & 68.1 \\
\hline 7 & 67.7 & 68.4 & 68.8 & 68.3 & 68.4 \\
\hline
\end{tabular}

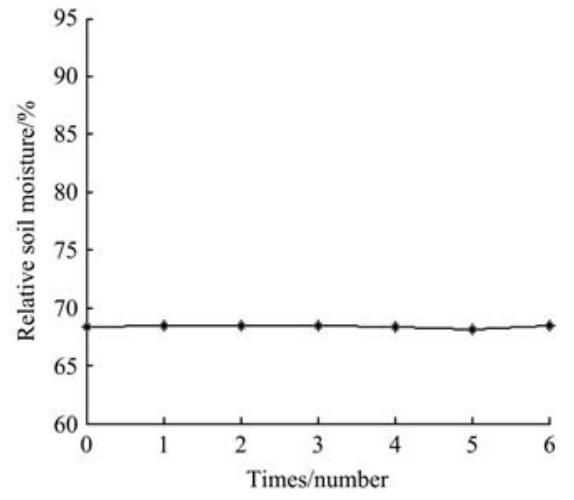

Figure 8 Plot of the weighted average value $\left(X^{+}\right)$

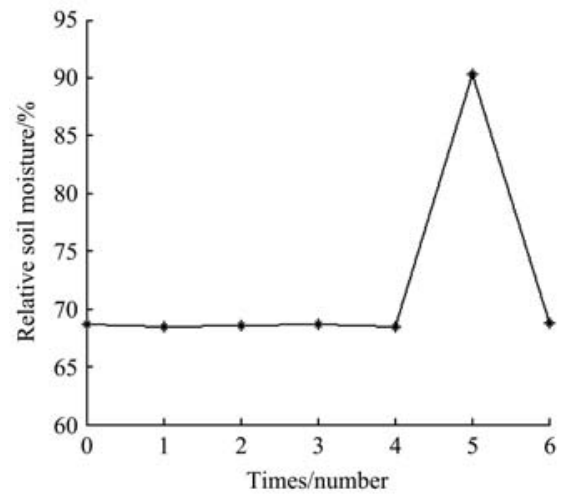

Figure 9 Plot of sensor 3

\subsection{Automatic control watering test}

\subsubsection{Matlab simulation}

Based on the mentioned fuzzy control theory, the simulation model of the relative soil moisture control was built in Matlab Simulink. The model of controller is shown in Figure 10.

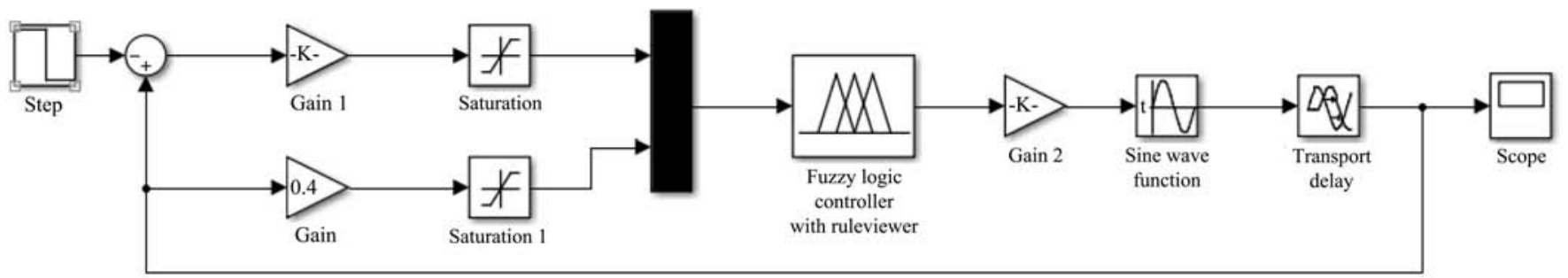

Figure 10 Simulation model of fuzzy control system 
The output characteristic is shown in Figure 11, the percent overshoot is low, and the relative soil moisture can be maintained near the humidity $(65 \%)$.

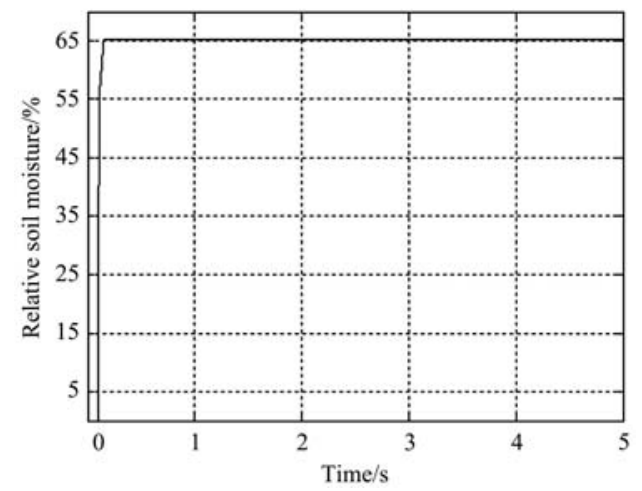

Figure 11 Automatic watering control simulation diagram

3.2.2 The watering performance test

The humidity was collected four times at fixed moments every day. The real-time collected humidity data are recorded in Table 2. The corresponding curve is shown in Figure 12.

Table 2 Real-time collected data

\begin{tabular}{ccccc}
\hline & \multicolumn{4}{c}{ Measure No. } \\
\cline { 2 - 5 } Day & 1 & 2 & 3 & 4 \\
\hline 1 & 72.9 & 72.6 & 70.6 & 68.4 \\
2 & 65.8 & 65.7 & 70.7 & 70.3 \\
3 & 68.1 & 66.5 & 66.3 & 66.2 \\
4 & 65.6 & 65.3 & 65.0 & 69.8 \\
5 & 67.2 & 67.0 & 66.2 & 69.8 \\
6 & 67.8 & 67.5 & 66.4 & 66.2 \\
7 & 65.1 & 68.3 & 65.5 & 64.3 \\
8 & 66.8 & 66.5 & 65.4 & 65.3 \\
\hline
\end{tabular}

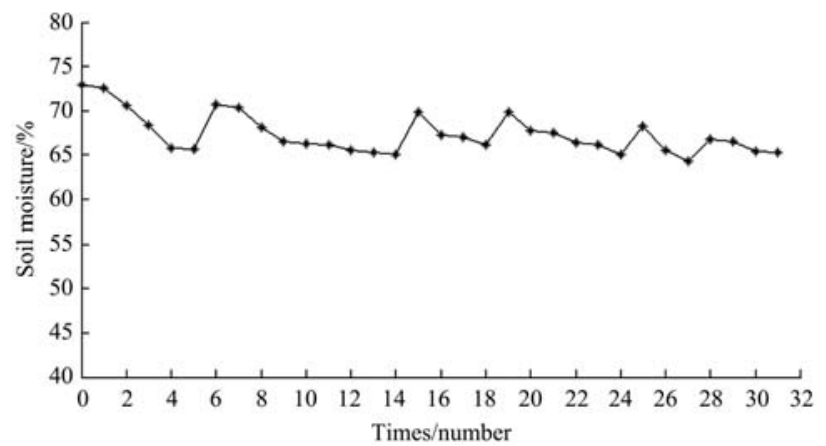

Figure 12 Real-time collected data

From Figure 11 and the Figure 12, it can be seen that the practical results and the expected results are essentially coincident. The relative soil moisture of flower can be maintained well in the vicinity of $65 \%$. As shown in Figure 12, when the soil moisture curve changes from declining trend to rising trend, the fuzzy control system certainly makes an accurate control decision and responds quickly to open the solenoid valve for watering. Then the soil moisture rapidly increases to a certain extent. So this fuzzy control system has a good adaptability to the change of soil moisture.

\subsection{Supplementing light test}

The average light of each area are recorded in the Table 3 when the smart flowerpot performs the light detection with counterclockwise rotation. In order to verify the accuracy of the supplementing light, the rotating angle of flowerpot is measured.
Table 3 Supplementing illumination test

\begin{tabular}{cccccccc}
\hline & \multicolumn{4}{c}{ Area/(lx) } & & Measured \\
No. & \multicolumn{4}{c}{ Angle $/\left(^{\circ}\right)$} & $\begin{array}{c}\text { Theory } \\
\text { angle } /\left(^{\circ}\right)\end{array}$ & $\begin{array}{c}\text { Error } \\
\text { Angle } /\left({ }^{\circ}\right)\end{array}$ \\
\cline { 2 - 7 } & $\mathrm{a}$ & $\mathrm{b}$ & $\mathrm{c}$ & $\mathrm{d}$ & & & -3 \\
2 & 455 & 484 & 85 & 413 & 267 & 270 & 0 \\
3 & 530 & 521 & 496 & 502 & 0 & 0 & 0 \\
4 & 99 & 457 & 383 & 395 & 93 & 90 & 3 \\
5 & 368 & 60 & 375 & 401 & 178 & 180 & -2 \\
\hline
\end{tabular}

As shown in Table 3, the practical measurement angle was nearly close to the theoretical calculation angle, and the error angle ranged from $-3^{\circ}$ to $3^{\circ}$. It means that the flowerpot can achieve the accurate supplementary illumination to ensure that the light is well-distributed on the flower.

\section{Conclusions}

Based on STM32 microcomputer and the key environmental factors that affect the growth of flowers, a novel and smart automatic light-seeking flowerpot for monitoring flower growth environment was designed. Through the experimental analysis, it was certain that the smart flowerpot can perform well on multi-channel information acquisition, information configuration, LCD display, automatic watering control, automatic light-seeking and light-supplementing control, data sending and receiving, and mobile APP operating. So the design of smart flowerpot is feasible. It can create a comfortable environment for the healthy growth of flowers.

\section{Acknowledgements}

This research was supported by the National Natural Science Foundation of China (No. 31101080), China Postdoctoral Science Foundation (No. 2015M580254, No. 2017T100221), Heilongjiang Postdoctoral Science Foundation (No. LBH-Z15011), Harbin Science and Technology Innovation Youth Talents Special Fund (No. 2015RQQXJ094), “Academic Backbone” Project of Northeast Agricultural University (No. 15XG12), and Northeast Agricultural University Doctoral Start-up Fund (No. 2012RCB51). The authors would like to thank the anonymous reviewers for their helpful suggestions, which greatly improved the paper.

\section{[References]}

[1] Zhang N, Wu W F, Du J S, Gu B J, Xing Z Q. Research status and development prospect of smart flowerpot. Agriculture and Technology, 2016; 36(1): 174-176. (in Chinese)

[2] Chen Y, Shi Y L, Wang Z Y, Huang L. Connectivity of wireless sensor networks for plant growth in greenhouse. Int J Agric \& Biol Eng, 2016; 9(1): 89-98.

[3] Shukla S, Yu C Y, Hardin J D, Jaber F H. Wireless data acquisition and control systems for agricultural water management projects. Horttechnology, 2006; 16(4): 595-604.

[4] Feng Z G, Lam J, Yang G H. Optimal partitioning method for stability analysis of continuous/discrete delay systems. International Journal of Robust \& Nonlinear Control, 2013; 25(4): 559-574.

[5] Wu T L, Wang Z Y, Zheng J H, Yu L, Bi C G. The design of intelligent flowerpot based on ARDUINO. Agriculture Network Information, 2016; 2: 34-37. (in Chinese)

[6] Lea-Cox J D, Belayneh B E. Implementation of sensor-controlled decision irrigation scheduling in pot-in-pot nursery production. Acta Horticulturae, 2014; (1034): 93-100.

[7] Zhang Z Q, Zhang W A, Wang Q, Zou W. Design and experiment of potted plants automatic irrigation system - based on PLC. Journal of Agricultural Mechanization Research, 2014; 10: 112-114, 119. (in Chinese) 
[8] Ji J X. Study on remote wireless smart pot system based on ZIGBEE+MQTT. International Journal of Future Generation Communication and Networking, 2016; 9(5): 1-8.

[9] Zhang J, Chen J, Cai Z J. Greenhouse temperature collection based on multi-sensor date fusion technology. Microcomputer Information, 2007; 01S: 153-154. (in Chinese)

[10] Fan D H, Li X L. Application of normalized weighted average algorithm in temperature acquisition system. Mechanical Engineering and Automation, 2012; 3: 115-116, 118. (in Chinese)

[11] Yan H, Tang Z J, Xing Z, Gao D N, Hong H X. Design of soil moisture distribution sensor based on high-frequency capacitance. Int J Agric \& Biol Eng, 2016; 9(3): 122-129.

[12] Munyaradzi M, Rupere T, Nyambo B, Mukute S, Chinyerutse M, Hapanga $\mathrm{T} \mathrm{B}$, et al. A low cost automatic irrigation controller driven by soil moisture sensors. International Journal of Agriculture Innovations and Research, 2013; 2(1): 1-7.

[13] Sun Y R, Dao-Kun M A, Lin J H, Lammer P S, Damerow L. An improved frequency domain technique for determining soil water content. Pedosphere, 2005; 15(6): 805-812.

[14] Soulis K X, Elmaloglou S, Dercas N. Investigating the effects of soil moisture sensors positioning and accuracy on soil moisture based drip irrigation scheduling systems. Agricultural Water Management, 2015; 148: 258-268.

[15] Martin D E, Lopez Jr J D, Lan Y B. Laboratory evaluation of the Green SeekerTM handheld optical sensor to variations in orientation and height above canopy. Int J Agric \& Biol Eng, 2012; 5(1): 43-47.

[16] Martin K L, Girma K, Freeman K W, Teal R K, Tubańa B, Arnall D B, et al. Expression of variability in corn as influenced by growth stage using optical sensor measurements. Agronomy Journal, 2007; 99(2): 384-389.

[17] Kim Y, Evans R G, Waddell J. Evaluation of in-field optical sensor for nitrogen assessment of barley in two irrigation systems. ASAE Section Meeting, Alberta, Canada, 2005.

[18] Xu T Y, Qin X S. A sequential fuzzy model with general-shaped parameters for water supply-demand analysis. Water Resources Management, 2015; 29(5): 1431-1446.

[19] Sakthivel R, Sundareswari K, Mathiyalagan K, Santra S. Reliable Hळ, stabilization of fuzzy systems with random delay via nonlinear retarded control. Circuits, Systems, and Signal Processing, 2016; 35(4): 1123-1145.

[20] Sun J, Zhang M X, Li Z M, Wu X H. Simulation of smith fuzzy PID temperature control in enzymatic detection of pesticide residues. Int $\mathrm{J}$ Agric \& Biol Eng, 2015; 8(1): 50-56.

[21] Du R C, Gong B C, Liu N N, Wang C C, Yang Z D, Ma M J. Design and experiment on intelligent fuzzy monitoring system for corn planters. Int $\mathrm{J}$ Agric \& Biol Eng, 2013; 6(3): 11-18.

[22] Han W T, Xu Z Q, Zhang Y, Chen X W, Ooi S K. Real-time remote monitoring system for crop water requirement information. Int J Agric \& Biol Eng, 2014; 7(6): 37-46.

[23] Mathiyalagan K, Sakthivel R, Marshal Anthoni S. Exponential stability result for discrete-time stochastic fuzzy uncertain neural networks. Physics Letters A, 2012; 376(8-9): 901-912.

[24] Wu C C, Zhou L, Wang J, Cai Y P. Smartphone based precise monitoring method for farm operation. Int J Agric \& Biol Eng, 2016; 9(3): 111-121.

[25] Riquelme J A, Soto F, Sanchez P, Iborra A, Vera J A. Wireless sensor networks for precision horticulture in southern Spain. Computers and Electronics in Agriculture, 2009; 68(1): 25-35. 